\title{
The Extend of Adaptation Bloom's Taxonomy of Cognitive Domain In English Questions Included in General Secondary Exams
}

\author{
Mohammad Akram Alzu'bi \\ English Department, Ajloun University College, AL-Balqa Applied University, Jordan \\ E-mail: dralzubi1978@bau.edu.jo
}

\author{
Doi:10.7575/aiac.alls.v.5n.2p.67 \\ URL: http://dx.doi.org/10.7575/aiac.alls.v.5n.2p.67
}

Received: 07/02/2014

Accepted: 28/03/2014

\begin{abstract}
The study aimed at analyzing English questions of the Jordanian Secondary Certificate Examinations via Blooms' cognitive levels. An analysis sheet was prepared by the researcher for the purpose of the study, which was ensured to be valid and reliable. The whole questions of the general secondary examinations for English course in both levels (level three and level four) during 2010-2013 composed the sample of the study. Frequencies and percentages were tabulated to facilitate the analysis of the results. The result of the study revealed that the total percentage of the first three levels (comprehension, knowledge, and analysis) is (69.6) but the total percentage of the last three levels (application, synthesis, and evaluation) is (30.4) so it indicated that the English questions included in general secondary examinations emphasize low order thinking levels. The researcher recommended that the questions designers should improve their questioning techniques in writing questions of exams.
\end{abstract}

Keywords: Analyzing; Secondary Certificate Examinations; Bloom's Taxonomy; Low level; High level

\section{The introduction}

The secondary stage is considered to be the last stage in the student's life. The Ministry of Education in Jordan takes care of this stage because the university acceptance depends on the average of this stage and the students' desires, so the successful candidate also can move from school stage to the university program. Also it prepares the students for the knowledge and basic skills required to meet society's needs.

English is one of the obligatory subjects in all streams because it is dominant language and required international language of communications, science, information technology, business, and entertainment. To measure what students learn of knowledge and experiences, teachers use achievement exams to carry out the purposes, so the achievement exams contribute in improving the learning process (Abu Hwaij \&et.al, 2002). Thus, it is necessary to prepare and build the exams correctly to help the teachers and students. However, most of the questions designers are not trained so the exams become uncompleted and do not meet the hopeful goals (Adas, 1999). The teachers should recognize the goals to achieve them through recognizing the characteristics of the learners, their needs, and attitudes. They should include different questions taken from the textbook to improve the students' ability to have critical thinking and decision making. And one way of improvement is through the questions presented in the exams (Franklin, 1982). However, there are several classifications in the field of evaluating and analyzing tests questions. For example, Bloom's Classification of Cognitive skills (Bloom's Taxonomy) is the most common one.

Benjamin Bloom created Bloom's Taxonomy during the 1950s to categorize the levels of reasoning skills required in classroom situations. It includes six levels of cognition that are ordered hierarchically; these levels are knowledge, comprehension, application, analysis, synthesis, and evaluation. The teacher and exam designers should adopt the whole cognitive levels in writing the tests. They should not write only tests to assess low levels like knowledge, comprehension, and application, but also to measure high levels and to use them in the lesson plans and tests.

Kelly (2014) claims that there are many reasons why some teachers fail to move students up the levels of Bloom's Taxonomy as follows: "For example, a teacher might have low expectations concerning the students' abilities. This is just sad and becomes a self fulfilling prophecy. Another reason might be that it can become difficult and time consuming for the teacher. It is a complete truth that it is much easier to grade assignments based on the lower levels than on the higher levels. In fact, as you move up Bloom's Taxonomy, you will find that rubrics become more important to ensure fair, accurate, and quick grading".

The researcher has noticed that there are shortcomings of experts and researchers in studying, analyzing and evaluating the English questions of Jordanian Secondary Certificate Examinations (SCE). He does not find studies investigate the degree of suitability of Bloom's levels distribution on English paper questions in the light of accurate and controlled standards. Thus, the present study attempts to analyze and evaluate English questions of (SCE) in the light of Bloom's classification of cognitive skills. Also, there is a complain of English secondary certificate questions and its variation; so, the researcher conducted the study to analyze English questions of the Jordanian (SCE) in the light of Blooms' cognitive levels. 
- To what extent is the availability of the cognitive goals levels according to Bloom's taxonomy in English Questions of the general secondary exams in Jordan?

\subsection{The significance of the study}

The significance of the study derived from the following points: Firstly, the study provides other researchers with some reliable instruments, action procedures, and experimental findings for use in future research. Secondly, the results help to develop the questions of (SCE). Thirdly, the study helps the exams designers to discover if the cognitive purposes levels are available in (SCE) or not.

\subsection{Operational Definitions}

The researcher adopted the following terms:

SCE: is a measurement tool used by Ministry of Education to measure the students' achievement.

Candidates for the exam: are the students enrolled in the second secondary grades.

Bloom's taxonomy: is a classification system of educational objectives based on the level of student's understanding that is necessary for achievement or mastery. It contains six levels, with the principle that competence at a higher level implies a reasonable degree of competence at the lower levels.

Analyzing: is an organized scientific style aims at describing the purposes of cognitive domain according to Bloom's classifying English Questions of (SCE).

\subsection{The limitations of the study}

It is possible to generalize the results of the study in the light of the following limitations:

- English Questions of the Jordanian (SCE) during the period 2010-2013 in level three and level one.

- The analytic card for analyzing the six levels of Bloom's classification.

\subsection{Procedures}

The researcher follows the following procedures:

- Designing a card to analyze the English questions.

- Making content validity of the instrument by giving it to a group of experts.

- Asking a group of analyzers to make sure of the reliability of analysis specialized in English language and education.

- Reading the questions accurately in order to recognize the included cognitive levels.

- Analyzing the questions depending on the previous levels.(if the questions contain several branches, each branch is treated as an independent question)

- Finding the questions frequencies depending on the analytical categories.

- Making the statistical treatment to find out the percentages.

- Showing the results and proposing suggestions

\section{The related studies}

Igbaria (2013) conducted a study aimed at analyzing the English textbook Horizons for 9th-grade students. It examines the variety in the cognitive level represented by the WH-questions in the textbook according to Bloom's taxonomy. Thus, the study tries to answer to what extent the WH-questions in the six levels of the cognitive domain are varied or frequent in the textbook of Horizons. After gathering, listing, and analyzing the questions according to Bloom's Taxonomy, the researcher calculated the percentage and frequencies in which each level of cognition appeared for units. The findings indicated that 244 questions emphasized levels of cognition representing lower order thinking skills, while only 137 questions emphasized the three higher order thinking ones.

Abd-Alaziz (2011) conducted a study that attempted to answer "what is the availability of the cognitive goals levels according to Bloom's classification in the secondary examination questions in the Islamic couture course in Jordan? The researcher designed analytical card according to Bloom's classification and used the method of content validity to establish validity and reliability is also calculated. The sample includes the questions of the general examination for Islamic culture in Jordan from 2005to 2011. The findings revealed that the percentage of comprehensive and remembering questions is (73.8\%) and the percentage of application, analyzing, synthesis, and evaluation is (26.2). Based on the results of the study, the research suggested decreasing the use of low level questions.

Swedan, K. (2009) conducted study aimed at analyzing and classifying the questions of geography in the first secondary grade in Syria according to Bloom's classification, the questions are classified into upper mental abilities and lower mental abilities. The sample of this study consists of the mentioned geographic questions in the geography course of the first secondary grade in the schools of Syria. The results showed that most of the questions focus on low level of thinking, so the percentage of understanding was $60.24 \%$, while the questions didn't indicate the levels of analysis and synthesis. Also, the percentage of evaluation level was very low $(0.86 \%)$.

Quthah et.al (2007) conducted a study aimed at evaluating the Islamic sciences questions included in the Jordanian 
secondary certificate examinations in the light of Bloom's classification. The instrument of analysis was prepared by the researcher. The results indicated that most of the questions focused on comprehension, knowledge and analysis. But application, synthesis and evaluation levels were not found. Most of the questions used were of: (a) the objective types (true, false, multiple-choice, and matching). (b): subjective types (short-answer, open-ended questions). None of the questions used were of the completion type. In the light of the findings, the researchers recommended the necessity of having measurement and evaluation experts in writing questions of exams and other recommendations built on the results.

Mohnot (2006) carried out a study aimed at examining the use of Bloom's Taxonomy of Educational Objectives (Cognitive Domain) in the Indian Certificate of Secondary Education (ICSE). This study categorized the thinking skills required to solve ICSE English Literature exam questions at four points (phases) during the lifetime of the exam. The findings found an increase in the questions of low level and a decrease in the high level ones. Also, 90\% of the questions was at two lowest levels (knowledge and comprehension).

Azari,(2005) conducted a study aimed at comparing the physics questions included in the university entrance exam with the questions included at the physics courses at high schools according to Bloom's Taxonomy. The sample of this study consists of a set of questions from included in University Entrance Exams and high school. The findings indicated that physics questions asked at Turkish University Entrance Exams concentrate on application, analysis, synthesis and evaluation and the high school questions concentrate on knowledge, comprehension and application.

Sevilay and et.al. (2003) conducted a study aimed at analyzing and comparing the chemistry questions at three types of schools with the university entrance examination according to Bloom's classification. After analyzing the questions statistically, the results revealed the following: firstly, $96 \%$ of the questions were of the lower levels. Secondly, more than half of the questions asked in the university entrance examination (OSS) were of the high levels.

The present study is similar to the former related studies in analyzing the secondary questions according to Bloom's taxonomy and adopting the analytical descriptive approach. For the researcher's knowledge, the study is different from the former related studies because it is conducted on the English questions included in general secondary exams in Jordan during the period (2010-1013).

\section{Method and Procedures}

\subsection{The subject of the study}

The sample of the study consists of English questions used in the (SCE) in Jordan for years (2010-2013) that were prepared by Ministry of Education. It includes (11) exams in two levels (L3+L4) in

summer and winter of the last four years.

\subsection{Instruments of the study}

For the purpose of the study, two instruments has been used which was analytical card and adopted standard of Bloom's taxonomy. Firstly, the analytical sheet includes the following Bloom's levels in cognitive domain for English questions: remembering, understanding, application, analysis, synthesis, and evaluation (see appendix 1). Thus, the questions are classified according to these levels in frequencies and percentages forms. Secondly, to find if the obtained percentage of each level in the English exam is appropriate or not, the researcher used refereed adoption standard of Bloom's taxonomy (see appendix 2).

\subsection{Validity and reliability of the instruments}

The instruments were content validated by a panel of experts who specialized in methods, curricula, evaluation and assessment. Criticism and comments on the original draft of the analytical sheet and the standard were solicited from a number of experts from Jordanian universities (public and private university). On the basis of the jury's feedback, modifications were made and mistakes were corrected. After making the validity of the study instruments, the researcher wanted to be sure of the reliability by analyzing three samples of the questions then he selected three experts to reanalyze the three samples again. Then the percentage of agreement between the researcher classification and every expert's one was computed. It's found that the percentage of the reliability between the researcher and the three experts was as following:

$0,88 \quad 0,93 \quad 0,89$

The average was $(0,90)$. Thus, the percentage is high and indicates the agreement between the judgers and the researcher in classifying the questions according to their attitudes and levels.

\subsection{Statistical treatment}

The researcher used analytical descriptive approach because it's suitable for the study.

\section{The results}

To answer the question of the study, the researcher compared the following percentages of cognitive domain purposes with the refereed adoption standard of Bloom's taxonomy: 
Table 1. The frequencies and the general percentages of cognitive domain purposes according to Bloom's taxonomy for the total of English Questions of the General Secondary exams for years (2010-2013)

\begin{tabular}{lll}
\hline Bloom's Cognitive Categories & Frequency & Percentages \\
\hline Knowledge & 58 & $15.4 \%$ \\
\hline Comprehension & 124 & $33.1 \%$ \\
\hline Application & 79 & $21.1 \%$ \\
\hline Analysis & 31 & $8.3 \%$ \\
\hline Synthesis & 59 & $15.7 \%$ \\
\hline Evaluation & 24 & $6.4 \%$ \\
\hline Total & 375 & $100 \%$ \\
\hline
\end{tabular}

As seen in Table 1, the number of collected questions is 375 . It can be understood that the percentage (15.4\%) of these questions is at knowledge level, $33.1 \%$ is at comprehension, $21.1 \%$ is at application, $8.3 \%$ is at analysis. Also, $15.7 \%$ is synthesis and $6.4 \%$ is at evaluation level.

Table 2. Distribution of the frequencies percentages of the examination questions according to the cognitive levels.

\begin{tabular}{|c|c|c|c|c|c|c|c|c|}
\hline Year & Session & Knowledge & $\begin{array}{l}\text { Comprehe } \\
\text { nsion }\end{array}$ & Application & Analysis & Synthesis & Evaluation & Total \\
\hline \multirow[t]{3}{*}{2010} & $\begin{array}{l}\text { Summer } \\
\text { (level 3) }\end{array}$ & $1.6 \%$ & $3.2 \%$ & $1.33 \%$ & $.54 \%$ & $1.33 \%$ & $.8 \%$ & $8.8 \%$ \\
\hline & $\begin{array}{l}\text { Summer } \\
\text { (level 4) }\end{array}$ & $1.33 \%$ & $2.66 \%$ & $1.6 \%$ & $.8 \%$ & $1.6 \%$ & $.54 \%$ & $8.53 \%$ \\
\hline & $\begin{array}{l}\text { Winter } \\
\text { (level 3) }\end{array}$ & $1.33 \%$ & $2.93 \%$ & $1.33 \%$ & $1.33 \%$ & $1.6 \%$ & $.54 \%$ & $9.06 \%$ \\
\hline \multirow[t]{4}{*}{2011} & $\begin{array}{l}\text { Summer } \\
\text { (level 3) }\end{array}$ & $1.6 \%$ & $2.4 \%$ & $1.33 \%$ & $.8 \%$ & $1.6 \%$ & $.54 \%$ & .8 .27 \\
\hline & $\begin{array}{l}\text { Summer } \\
\text { (level 4) }\end{array}$ & $1.33 \%$ & $2.4 \%$ & $1.86 \%$ & $.54 \%$ & $1.06 \%$ & $.54 \%$ & $7.73 \%$ \\
\hline & $\begin{array}{l}\text { Winter } \\
\text { (level 3) }\end{array}$ & $1.06 \%$ & $2.93 \%$ & $2.4 \%$ & $.54 \%$ & $1.06 \%$ & $.54 \%$ & $8.53 \%$ \\
\hline & $\begin{array}{l}\text { Winter } \\
\text { (Level 4) }\end{array}$ & $1.06 \%$ & $2.93 \%$ & $1.86 \%$ & $.54 \%$ & $.8 \%$ & $.54 \%$ & $7.73 \%$ \\
\hline \multirow[t]{2}{*}{2012} & $\begin{array}{l}\text { Winter } \\
\text { (Level 4) }\end{array}$ & $1.33 \%$ & $2.14 \%$ & $1.6 \%$ & $1.06 \%$ & $1.06 \%$ & $.54 \%$ & $7.73 \%$ \\
\hline & $\begin{array}{l}\text { Winter } \\
\text { (Level 3) }\end{array}$ & $1.33 \%$ & $2.93 \%$ & $1.86 \%$ & $.54 \%$ & $1.6 \%$ & $.27 \%$ & $8.53 \%$ \\
\hline \multirow[t]{3}{*}{2013} & $\begin{array}{l}\text { Summer } \\
\text { (level 3) }\end{array}$ & $1.33 \%$ & $2.93 \%$ & $2.14 \%$ & $.26 \%$ & $1.33 \%$ & $.54 \%$ & $8.53 \%$ \\
\hline & $\begin{array}{l}\text { Winter } \\
\text { (Level 3) }\end{array}$ & $1.06 \%$ & $2.66 \%$ & $2.14 \%$ & $.8 \%$ & $1.33 \%$ & $.54 \%$ & $8.53 \%$ \\
\hline & $\begin{array}{l}\text { Winter } \\
\text { (Level 4) }\end{array}$ & $1.06 \%$ & $2.93 \%$ & $1.6 \%$ & $.54 \%$ & $1.33 \%$ & $.54 \%$ & $8 \%$ \\
\hline
\end{tabular}

As seen in Table 2, the percentages of Bloom's cognitive levels are slightly the same in all years, e.g. the percentage of knowledge level is between $1.06 \%$ and 1.6 for years (2010-2013), the percentage of comprehension level is between 2.14 and 3.2 and so. Thus, the percentages are very approximate in all years.

\section{Discussion and Implication}

The findings of the study revealed that all levels of Bloom's taxonomy are adopted to determine students' achievements. It can be seen that $69.6 \%$ of English exam questions at first three levels. However, the percentage of the exam 
questions at last three levels is $30.4 \%$. By comparing the percentages of cognitive domain purposes with the refereed adoption standard of Bloom's taxonomy, it is found that the total percentage of the first three levels (69.6) is higher than the total percentage of the refereed adaptation standard of Bloom's taxonomy $(60 \%)$ and the total percentage of the last three levels (application, synthesis, and evaluation) is (30.4) which is lower than the total percentage of the refereed adaptation standard of Bloom's taxonomy (40\%). Also, the calculated percentages of knowledge, analysis, and evaluation $(15.4 \%, 8,3 \%$, and 6.4$)$ are lower than the percentages of the refereed adoption standard of Bloom's taxonomy $(22 \%, 17 \%$ and $10 \%)$. On the other hand, the percentages of comprehension, application, and synthesis ( 33.1 $\%, 21.1 \%$ and $15.7 \%)$ are higher than $(20 \%, 18 \%$ and $13 \%)$.

It means that the Ministry of Education focuses on the low levels (except knowledge) in one hand and decreases the high levels (except synthesis) on the other hand. So, the calculated percentages are not accepted because this distribution reflects a fact that there is no balance in the questions. Also, this conclusion leads to the basic problem that students are motivated to remember and makes teachers imitate the questions, neglect the high levels, and focus on the low level. It is possible to see the similar results in most literature e.g. Swedan, 2009, Igbaria, 2013 and Abd-Alaziz, 2011 who claim that most of the questions emphasized low order thinking skills.

The questions at lower level are generally preferred by instructors to evaluate their students' understanding. Also, the students complain about the higher level questions with indirect answers. They prefer lower level questions related to the content of the book directly because the students want marks to enter the university after the secondary stage. The reason may be either caused by the weakness of the content nature of English subject or by the experience weakness of the English secondary questions designers in the fields and levels of the purposes.

The modern trend in education concentrates on shifting from teacher-centered approach to learner-centered approach so the questions should concentrate on high levels of thinking instead of low levels of thinking. It is necessary for the questions to be suitable for the all thinking levels to achieve the harmony and agreement. Ministry of education should also take into account the age and mental periods that lead to an effective critical thinking especially in secondary stage which requires high levels of thinking.

\section{Recommendations}

- The designers of English questions, included in the secondary examination, should decrease the amount of comprehension, application, and synthesis questions and increase the questions of knowledge, analysis, and evaluation.

- The Ministry of Education should make training courses for teachers and the questions designers to be able to deal with Bloom's classification.

- Conducting new studies on English subject questions in different stages and levels.

\section{References}

Abu Hwaij, M.; Alkhateeb, A.; \& Abu-Meghli, S. (2002). The Measurement and Evaluation in Education and Psychology: Amman, Dar Althakafah for Publishing.

Adas, A. (1999). Psychology: Modern View: Amman, Dar Alfeker for Publishing.

Azari, A. (2005). Analysis of Turkish High-School Physics-Examination Questions and University Entrance Exams Questions According to Blooms' Taxonomy. Turkish Science Education, (2) 2.

Franclin, D. (1981). An Analysis of Questions in Sixth-Grade Social Studies Textbooks Published between 1965-1969 and 1975-1979. Published Dissertation. Indian University.

Igbaria, A. (2013). A Content Analysis of the WH-Questions in the EFL Textbook of Horizons. International Education Studies.(6)7.doi:10.5539/ies.v6n7p200,http://dx.doi.org/10.5539/ies.v6n7p200

Kelly, M. (2014). Bloom's Taxonomy in the Classroom. . [Online] Available http://712educators.about.com/od/testconstruction/p/bloomstaxonomy.htm

Mohnot, A. (2006). 'Seeing the Bigger Picture': Higher Order Cognition in the Indian Certificate of Secondary Education (ICSE) English Literature Examination. (Master Degree). Stanford University.

Nguyen, C. (2008). Using Bloom's revised taxonomy to design in-class reading questions for intermediate students in the context of Vietnam. Journal of Science, Foreign Languages. 24. 175-183

Quthah, A.; Al-Masha'leh, M. \& Alkhawaldeh, N. (2007). An Analytical and Evaluative Study of the Islamic Sciences Questions Used in the Jordanian General Secondary Certificate Examinations for Years (1997-2005) in Light of Cognitive Levels. Journal for Research. (2)

Sevilay, K.; Serkan, S.; Orhan, K. \& Salih Ç. (2003). Analysis of Turkish High-school Chemistry-examination questions according to Bloom's Taxonomy. Chemistry Education: Research and Practice. (4) 1. 25-30

Swedan, K. (2009). An Analytical and Evaluative Study of the Natural Geography Used in the First Secondary Grade in Syria in Light of Blooms' Taxonomy. Journal of Damascus University. (25) 1+2. 
Appendix (1)

Analytical Card of English Questions included in General Secondary exams

According to Bloom's Classification

\begin{tabular}{|l|l|l|l|l|l|l|}
\hline $\begin{array}{l}\text { Question } \\
\text { Number }\end{array}$ & knowledge & Comprehension & Application & Analysis & Synthesis & Evaluation \\
\hline & & & & & & \\
\\
\end{tabular}

Appendix (2)

Refereed adoption standard of Bloom's taxonomy

\begin{tabular}{l|l}
\hline Level & Percentage \\
\hline Knowledge & $22 \%$ \\
\hline Comprehension & $20 \%$ \\
\hline Application & $18 \%$ \\
\hline Analysis & $17 \%$ \\
\hline Synthesis & $13 \%$ \\
\hline Evaluation & $10 \%$ \\
\hline Total & $100 \%$ \\
\hline
\end{tabular}

